\title{
A REFORMA CURRICULAR E A MEMÓRIA IDEOLOGIZADA DE UMA GEOGRAFIA EM (DES) CONSTRUÇÃO
}

\author{
CURRICULAR REFORM AND IDEOLOGIZED MEMORY OF A GEOGRAPHY IN (DE) \\ CONSTRUCTION
}

\section{LA REFORMA CURRICULAR Y LA MEMORIA IDEOLOGIZADA DE UNA GEOGRAFIA EN (DE) CONSTRUCCIÓN}

\author{
José Rubens Mascarenhas de Almeida \\ Pós-doutor pela Universidade Nacional Autônoma do México. \\ Professor Doutor da Universidade Estadual do Sudoeste da Bahia (UESB). \\ Vitória da Conquista, BA - Brasil - Brasil. \\ joserubensmascarenhas@yahoo.com.br \\ Danilo Bandeira dos Santos Cruz \\ Mestrado em Memória: Linguagem e Sociedade pela \\ Universidade Estadual do Sudoeste da Bahia e Avaliador Educacional Técnico. \\ Salvador, BA - Brasil \\ danibande@yahoo.com.br
}

\begin{abstract}
RESUMO: As mudanças curriculares surgem como possibilidade de adequação à lógica de acumulação capitalista, visto que são capazes de direcionar o comportamento dos sujeitos no sentido da adaptação ao dinâmico metabolismo imposto pelo poder dominante, em especial, no processo de (re)organização do trabalho. Nessa direção, este estudo objetiva analisar esse processo a partir dos currículos que deram consistência e orientação ao curso de Licenciatura Plena em Geografia, da Universidade Estadual do Sudoeste da Bahia - UESB, ao longo desses 31 anos de existência (1985 - 2015). Para tanto, este trabalho se ampara em observações de campo - seleção/coleta dos documentos analisados e de conversas com professores que participaram da elaboração, análise dos dados, leituras e discussões. Além disso, a pesquisa alcança a memória, inscrita nos currículos analisados, a qual oculta/ expõe um movimento de (des)construção de uma geografia permanentemente em vias de consolidação, cuja trajetória esteve marcada por avanços e retrocessos.
\end{abstract}

PALAVRAS-CHAVE: Geografia. Licenciatura Plena. Uesb. Ideologia. Educação. Currículo.

ABSTRACT: The curricular changes arise as the possibility of suiting to the capitalist accumulation logic, since they are able to direct the subjects behavior in the sense of adapting to the dynamic metabolism imposed by the dominant power, especially, in the process of (re) organization of work. In this direction, this study aims to analyze that process from the curricula that gave consistency and guidance to the Full Degree in Geography course of the Universidade Estadual do Sudoeste da Bahia - UESB, over those 31 years of existence (1985 - 2015).Therefore, this work supports itself in field observations - time of selection/ collection of examined documents and conversations with teachers who took part in the elaborations, data analysis, readings and discussions. In addition, the research reaches the memory registered in the analyzed curricula, which hides/expose a movement of (de) construction of a geography permanently in process of consolidation, whose trajectory was marked by advances and backspace. KEYWORDS: Geography. Full graduation. Ideology. Uesb. Education. Curriculum.

RESUMEN: Los cambios curriculares surgen como posibilidad de adecuación a la lógica de la acumulación capitalista, ya que son capaces de dirigir el comportamiento de los sujetos en el sentido de la adaptación al dinámico metabolismo impuesto por el poder dominante, en especial en el proceso de (re)organización. En este sentido, este estudio tiene como objetivo analizar el proceso a partir de los currículos que dieron consistencia y orientación al Curso de Licenciatura en Geografía, de la Universidade Estadual do Sudoeste da Bahia - UESB, a lo largo de estos 31 años de existencia (1985-2015). Por lo tanto, este trabajo se ampara en observaciones de campo - selección/ recolección de documentos examinados y de conversaciones con los profesores que participaron de la preparación, análisis de datos, lecturas y discusiones. Además, la investigación llega a la memoria, registrada en los currículos analizados, que oculta/muestra un movimiento de (de) construcción de una geografía permanentemente en el proceso de consolidación, cuya trayectoria estuve marcada por avances y retrocesos.

PALABRAS CLAVE: Geografía. Licenciatura Plena. Uesb. Ideología. Educación. Currículo.

Artigo recebido em maio de 2017

Aprovado em julho de 2017 


\section{1| INTRODUÇÃO}

O atual momento da educação no Brasil envolve o debate mais amplo sobre a Base Nacional Comum Curricular - BNCC. Um documento proposto, de forma preliminar, pelo Ministério da Educação, baseado tanto nas Diretrizes Curriculares Nacionais, quanto no Plano Nacional de Educação, aprovado em 25 de junho de 2014, por meio da Lei $n^{\circ} 13.005$. Tal plano traz na estratégia 15.6 as seguintes considerações:

Promover a reforma curricular dos cursos de licenciatura e estimular a renovação pedagógica, de forma a assegurar o foco no aprendizado do (a) aluno (a), dividindo a carga horária em formação geral, formação na área do saber e didática específica e incorporando as modernas tecnologias de informação e comunicação, em articulação com a base nacional comum dos currículos da educação básica, de que tratam as estratégias 2.1, 2.2, 3.2 e 3.3 deste PNE. (BRASIL, 2015).

Dessa forma, o documento chama a atenção para a necessidade de uma reformulação dos currículos dos cursos de licenciatura, tendo como referência a Base Nacional Comum Curricular. O Brasil, portanto, vivencia mais um processo de redirecionamento do seu sistema educativo, fato relevante que merece a atenção por parte de toda a sociedade e, em especial, das comunidades escolares e acadêmicas, visto que toda mudança pressupõe intencionalidades e direcionamentos, cujos reflexos incidem, de modo bastante contundente, no cotidiano dos sujeitos.

Este artigo defende a ideia de que todo currículo é um instrumento de controle social, não neutro, refletor das contradições sociais, carregado de ideologias. Tais ideologias atuam como base da estrutura social, legitimando o aparato cultural historicamente cristalizado e, portanto, reafirmando o poder político e sua organização. No âmbito desse processo, a realidade se constitui na dinâmica de vida dos sujeitos em seu cotidiano, pois a regularidade, as repetições e as evidências, mantidas pelo ritmo comum da vida humana, acabam cunhando a consciência dos indivíduos de modo a tornar independente e natural o caráter dos fenômenos sociais e isto constitui o mundo da pseudoconcreticidade, da ideologia. É um claro-escuro de verdade e engano (KOSIK, 1976, p. 11).

Todo currículo é, ainda, um instrumento de ação política. Além disso, há de se pontuar que as teorizações do currículo revelam/escondem uma relação direta entre cada teoria e os momentos de adequação do processo de acumulação do capital, em particular, nos momentos de crise. Isto é, o esgotamento de determinado processo de acumulação capitalista faz emergir e aprofundar as crises estruturais do sistema e eclodir crises conjunturais e com elas, a necessidade de adequação - no caso aqui estudado, nos sistemas de ensino. Nota-se, nesse sentido, que a relação entre o aprofundamento da crise econômica mundial de 2008 e a posterior determinação definida em lei sobre a alteração curricular nacional não é mera coincidência, mas apresenta uma intencionalidade totalmente atrelada aos interesses mais amplos do sistema produtivo vigente.

Nessa perpectiva, as alterações curriculares verificadas ao longo da história da educação estiveram atreladas às necessidades de perpetuação, reprodução e territorialização dos mercados, cujas características contemporâneas alcançam a prevalência da financeirização da economia e da dinâmica da produção flexível. Nesse contexto, as desiguldades sócio-econômicas se ampliam e, como desdobramento, emerge o questionamento acerca da eficiência do Estado no atendimento das demandas sociais, dentre as quais, as relativas ao campo educacional, fato que abre o debate em torno da inevitabilidade da privatização das instituições de ensino, como preconiza o discurso neoliberal pautado na redução do controle do Estado.

Além disso, as crises permanentes do capital sugerem a busca constante por soluções, capazes de atender aos interesses dos atores hegemônicos e, neste sentido, as mudanças curriculares 
surgem como possibilidade de adequação à lógica de acumulação capitalista, visto que são capazes de direcionar o comportamento dos sujeitos no sentido da adaptação ao dinâmico metabolismo imposto pelo poder dominante, em especial no processo de (re)organização do trabalho.

Dessa forma, ao se considerar a nova reformulação curricular nacional em curso, proposta a partir da produção de uma Base Nacional Comum, é preciso estabelecer uma reflexão acerca da realidade dos cursos de formação de professores, tendo como referência os currículos desenvolvidos ao longo desses processos formativos. Nessa direção, cabe a percepção dos projetos de sociedade explícitos/implícitos, responsáveis por (des)orientar as práticas educativas dos profissionais do magistério. De modo particular, este artigo pretende analisar a realidade do Curso de Licenciatura plena em Geografia da Universidade Estadual do Sudoeste da Bahia - UESB - a partir dos currículos que deram consistência e orientação aos processos educativos dessa disciplina ao longo desses trinta e um anos de história (1985-2015), entendendo que a memória inscrita nos documentos gerados por este processo oculta/expõe contradições, disputas, resistências e ideologias. Oculta/expõe ainda o constante processo de construção de uma ciência geográfica "crítica" permanentemente em vias de consolidação, cuja trajetória esteve marcada por avanços e retrocessos.

\section{2 | A MEMÓRIA DO CURSO DE GEOGRAFIA DA UESB EXPRESSA EM CURRÍCULOS}

Para se compreender a dinâmica de criação do curso de Licenciatura Plena em Geografia da UESB, em 1985, é preciso partir da análise do período que antecede esse processo, ou seja, a década de 1970, quando o país vivia o contexto da ditadura civil-militar. O Estado brasileiro, seguindo as orientações da política de dominação estadunidense, promoveu uma significativa reformulação curricular, cujos reflexos alcançaram as disciplinas de geografia e história, as quais foram descaracterizadas, passando a compor o conjunto de conhecimentos desenvolvidos pelos Estudos Sociais (LEI, 2002).

Segundo documento da Secretaria de Educação e Cultura do Estado da Bahia (SEC/BA), Proposta de Programas de Ensino para a escola Normal/item Proposta de Programa de Ensino de Fundamentos e Metodologia do Ensino de História, foram realizadas algumas investigações sobre os currículos escolares de vários países e a disciplina Estudos Sociais só apareceu com este nome nos lugares que mantinham vínculos estreitos com os Estados Unidos da América (EUA). (OLIVEIRA, 2007, p. 22).

Com tal direcionamento, a vinculação brasileira com os EUA resultou no estabelecimento de um novo currículo para as escolas do país, com vistas para a formação de um comportamento coletivo pautado na passividade e permissividade. A apreensão destes valores visava, sobretudo, conformar os sujeitos à lógica perversa do sistema capitalista, num período marcado pela disputa ideológica entre Estados Unidos e União Soviética, bem como pela ditadura militar brasileira, resultante desse processo. As instituições de ensino do Brasil, por meio desse novo currículo, o qual promoveu o empobrecimento dos conteúdos de geografia e história, serviram de unidades fundamentais para a afirmação dos ideais de dominação estadunidenses, através do agenciamento do modo de pensar/agir dos sujeitos em vias de escolarização. Dessa forma, se evidenciava o caráter ideológico assumido pela disciplina Estudos Sociais, cuja contribuição para a conformação do totalitarismo engendrado pela ditadura foi fundamental.

No ano de 1985, quando a ditadura civil-militar entrou em processo de decadência, uma nova reformulação curricular foi estabelecida, promovendo as condições necessárias para a recondução das disciplinas de Geografia e História aos currículos das escolas de primeiro e segundo graus. 
Foi nesse contexto de transformações que o curso de Geografia da UESB foi implantado, nesse mesmo ano, tendo em vista atender às necessidades de formação de professores atuantes no Ensino Básico das escolas de Vitória da Conquista - BA - formação de mão de obra qualificada.

Essa realidade específica do curso de Geografia da UESB se relaciona diretamente com a dinâmica histórica da década de 1990. Após o processo de redemocratização do Brasil, verificou-se uma adequação mais intensa do Estado brasileiro à lógica neoliberal. Ao mesmo tempo em que se processava o sucateamento da educação pública, as instituições privadas de ensino superior se multiplicavam, numa via de mercantilização do saber, de acordo com a dinâmica fragmentada e produtivista dos mercados. Deste processo saíram movimentos contra-hegemônicos, os quais lutaram pela reforma universitária dos anos 2000. Entretanto, apesar da nova reforma, "o Estado permaneceu desempenhando o seu papel de regulamentador das políticas educacionais, sempre colado aos interesses de expansão capitalista" (RAMIRES, 2011, p. 72).

A questão posta, a partir de então, foi a de que era preciso preparar profissionais para atender às novas demandas (das empresas) do mundo contemporâneo, cada vez mais exigente. Para tanto, os governos brasileiros se aliaram às definições de organismos internacionais de financiamento como o Banco Mundial, visando corresponder às expectativas capitalistas. Isto feito sob a ideologia do desenvolvimento nacional. Daí se consolidou o processo de produção e de reordenação dos instrumentos de controle das ações pedagógicas das instituições de ensino. Assim, foram construídos e reconstruídos os currículos e avaliações de escolas e universidades, através de exames nacionais, como o Exame Nacional do Ensino Médio (ENEM), Exame Nacional de Cursos (Provão) e de parâmetros e diretrizes curriculares modeladores, dentre os quais se citam: a Lei de Diretrizes e Bases da Educação Brasileira - LDBEN (1996) e os Parâmetros Curriculares Nacionais (1997) (OLIVEIRA, 2007, p. 34).

Como desdobramento desse amplo movimento de mudanças no campo educacional do país, a Universidade Estadual do Sudoeste da Bahia, no início dos anos 2000, iniciou um processo de alteração curricular do curso de Geografia. Entendia-se que era necessário adequar o curso à realidade, marcada pelas profundas transformações de um novo tempo que surgia. Um tempo caracterizado pelo progresso técnico-científico, protagonizado pelas técnicas da informação, "que passaram a exercer um papel de elo entre as demais, unindo-as e assegurando ao novo sistema técnico uma presença planetária" (SANTOS, 2008, p. 23).

Esse contexto se refere à ampliação dos fluxos de informação, possibilitados pela materialização das chamadas "novas tecnologias". Tais condições materiais possibilitaram o ressurgimento de movimentos abrangentes de reformas, tais quais a do Estado, da economia (pelo redesenho da indústria, comércio, serviços), da infraestrutura (nova logística para os transportes e comunicação), da formação profissional e, por conseguinte, da Educação.

Essas transformações tiveram consequências diretas na dinâmica político-pedagógica das universidades do país e, no caso específico, nas formas de produção da ciência geográfica. Na Universidade Estadual do Sudoeste da Bahia, tal ciência estava envolvida pela atmosfera dos permanentes debates em torno dessa primeira reformulação curricular. Era preciso trazer para o centro das discussões novas temáticas, procedimentos de ensino, reflexões capazes de responder a questões tão complexas que traziam, para a esfera acadêmica, o debate acerca das novas formas de configuração espaço-temporal. Isto, porque a realidade concreta, marcada pelo processo de globalização e, por extensão, pelo desenvolvimento técnico-científico-informacional e os seus desdobramentos, não mais era capaz de ser explicada com as mesmas concepções que acompanharam a ciência geográfica desde os seus primórdios.

Cabia, portanto, a recondução da dinâmica de construção dos conhecimentos da geografia, no sentido de se alcançar uma ciência crítica, preocupada com a formação de sujeitos comprometidos 
com a transformação do mundo. Entretanto, de modo complementar, essa necessidade de recontextualização da geografia uesbiana se guiou, sobretudo, pelas exigências e limites impostos pelas novas normas que passaram a regulamentar a educação brasileira desde o final do século $\mathrm{XX}$, como as definidas pela LDBEN e os PCNs (1998).

Assim, depois de pontuadas as ponderações acerca das possibilidades e limitações estabelecidas na esfera legislativa, o currículo seguiu o seu processo de construção. Para tanto, considerou-se, antes de tudo, a necessidade de iniciar um movimento de avaliação do currículo anterior, pois que este esteve em vigor por longos quinze anos e, dessa forma, não se podia simplesmente ignorá-lo, sem qualquer reflexão.

Muitas questões emergiram nesse contexto, tais como: Quais os pontos em destaque merecedores de revisão, de permanência ou substituição, presentes na estrutura avaliada? Como a nova proposta poderia corresponder às demandas surgidas no interior da ciência geográfica? Quais os encaminhamentos necessários para tornar possível uma ciência capaz de promover uma melhor compreensão da realidade? Essas foram algumas das questões postas em discussão durante as reuniões de departamento e colegiado.

Em seguida, passou-se para o plano da produção escrita da versão inicial da proposta, isto é, um primeiro esboço do Projeto Pedagógico, dentro do qual o currículo estaria inserido. Nessa versão está exposta a análise preliminar do Curso de Licenciatura Plena em Geografia da UESB, delineando novos encaminhamentos político-acadêmico-pedagógicos para o curso e os objetivos a serem alcançados através das alterações.

A premissa da flexibilidade do currículo foi, também, considerada nessa dinâmica de reestruturação curricular, levando em consideração a "autonomia" acadêmica e tendo como objetivo "atender tanto às demandas da sociedade tecnológica moderna" - ou pós-moderna? - "quanto àquelas que se direcionam a uma dimensão criativa e emancipatória para a existência humana" (UNIVERSIDADE ESTADUAL DO SUDOESTE DA BAHIA, 2003). Estas duas passagens, presentes no Projeto Político Pedagógico de Geografia da UESB, expressam a dicotômica relação entre o sujeito que se prepara para a vida profissional e, que, portanto, deve se adequar às chamadas exigências do mercado e a sua formação crítica e, talvez, libertária. Mas, é possível separar, dentro do processo formativo do licenciado, esses dois aspectos? Tais elementos (sujeito e formação) não fazem parte de um mesmo processo, se relacionando de maneira indissociável e, com isso, ajudando a compor a capacidade de pensar/agir dos sujeitos que aprendem de modo abrangente? A dinâmica formativa do graduando em geografia deve se pautar pela integralidade dos aspectos que constituem tal dinâmica, caso contrário a distância entre teoria e prática se tornará cada vez mais ampla.

Existe também uma proclamada preocupação com os novos caminhos de atuação profissional do licenciado em geografia, inscrita no Projeto Pedagógico do curso (2003), que explicita uma reordenação curricular associada às reformas universitárias do final do século $X X$, que estiveram alinhadas, principalmente, às novas demandas do sistema produtivo. Este passou a se estruturar e dirigir as suas ações com base no advento das tecnologias de informação e comunicação, as quais promoveram uma série de modificações na dinâmica espaço/temporal, como já afirmado anteriormente. Assim, às universidades cabe o papel de recondicionar o perfil dos profissionais formados por elas, no sentido de oferecer um leque mais amplo de habilidades, já que o mundo - da mercadoria - o exige.

Desta forma, a preocupação com a formação de sujeitos capazes de lidar profissionalmente com diferentes aspectos da realidade - as chamadas multicompetências - está registrada no campo denominado Competências e Habilidades Essenciais (UNIVERSIDADE ESTADUAL DO SUDOESTE DA BAHIA, 2003): 


\begin{abstract}
Quando se pensa na utilidade social da geografia e o papel que o profissional da área cumpre ou pode vir a cumprir, imediatamente surge uma ampla variedade de temáticas e campos de atuação pelos quais o geógrafo transita com maior ou menor desenvoltura, lidando com coisas que vão desde as mais simples noções de orientação e localização até as mais sofisticadas técnicas de geoprocessamento, das inúmeras questões relativas ao desenvolvimento socioeconômico e à gestão do território, até as práticas pedagógicas adequadas ao aperfeiçoamento da cidadania.
\end{abstract}

Com tal característica, o curso de Geografia processava as transformações promovidas nas mais diferentes esferas, em especial na econômica, dentro da qual o mercado de trabalho se tornava cada vez mais diversificado, flexível e variável. Estes aspectos estavam associados aos propósitos específicos de formação docente do curso, que se baseavam numa sólida dinâmica de produção intelectual de discentes e professores, ao mesmo tempo em que proporcionava a maleabilidade da dinâmica formativa, no sentido de oferecer aos estudantes uma diversidade de campos de atuação profissional, como no exemplo da citação acima.

No entanto, essas mesmas considerações podem ser lidas de outra maneira. Apesar de o mercado de trabalho se mostrar cada vez mais restrito ao cientista social (PINTAUDI, 1999) o discurso dominante trata de promover o falseamento da realidade através da ideologia da flexibilização do trabalho e da abertura de novos campos, apoiando-se na ideia de que o acelerado ritmo de desenvolvimento tecnológico da atualidade tem permitido o surgimento de um conjunto bastante amplo de oportunidades de emprego - como os que são apresentados pelo currículo - cabendo aos sujeitos a responsabilidade de se prepararem para elas, tendo em vista a ampla concorrência existente. Trata-se, neste caso, de transferir a culpa do desemprego, por exemplo, aos indivíduos que não estudaram ou, se o fizeram, não fizeram de maneira suficientemente competente.

Diante desse complexo contexto, surgiram propostas/ações - escala federal - sobretudo verticalizadas, de redefinição dos processos educativos no âmbito das Instituições de Ensino Superior, que passaram a fazer parte de uma atmosfera marcada pela lógica das privatizações, do sucateamento do sistema público de ensino e da modelização dos instrumentos de avaliação da "qualidade" da educação, os quais contribuíram, e seguem no mesmo sentido, padronizando o conhecimento e controlando-o ainda mais. Tal controle revigora a reprodução de ideologias dominantes e, consequentemente, enfraquecem os movimentos contraideológicos em todas as esferas da sociedade.

Com isso, justifica-se a necessária dinâmica de reorientação curricular, pela qual diversas universidades do país passaram ao longo desse período (décadas de 1990-2000), dentre elas a Universidade Estadual do Sudoeste da Bahia, por meio da reforma do currículo do curso de Licenciatura Plena em Geografia. Portanto, é fundamental considerar todas as relações estabelecidas em torno das alterações processadas na estrutura curricular de tal curso para se compreender a sua dialética histórica.

Ao longo da reforma do currículo de geografia da UESB, os textos que apresentavam as alterações e justificativas tentaram tecer considerações acerca da autonomia universitária, além de compreender a reformulação como um processo que extrapola a simples inserção de novos conteúdos ou de "disciplinas eletivas". Entretanto, é preciso questionar até que ponto essas considerações contidas no discurso formalizado pelo documento (currículo) foram materializadas em práticas condizentes com o sentido pretendido pelos textos. Sabe-se que o currículo, como bem afirma o próprio PPG (UNIVERSIDADE ESTADUAL DO SUDOESTE DA BAHIA, 2003): "não pode deixar de ser percebido relacionalmente, como tendo adquirido significado a partir das conexões que mantêm com as complexas configurações de dominação e subordinação", pois ele é, também, expressão de conflitos, de resistências e oposições. 
A análise e compreensão da estrutura curricular, portanto, só podem ser alcançadas com êxito caso o pesquisador leve em consideração não apenas os textos que nele estão inseridos em forma de conteúdos, mas ao estudioso cabe ir além da forma, partindo à busca das conexões estabelecidas no âmbito das interações societárias, configuradas pela lógica das dominações/ resistências entre as classes desiguais definidas num dado tempo/espaço (APPLE, 1989). Sendo assim, é imprescindível ratificar a ideia de que, para se alcançar a compreensão da dinâmica de produção curricular situada dentro de um determinado contexto, é preciso conhecer o conjunto das relações, dentro das quais tal produção está inserida (GOODSON, 1995).

O currículo do curso de geografia foi organizado, em nome do didatismo, através da separação das diferentes áreas do conhecimento que alimentam o saber científico da geografia. Essa organização é justificada por meio do anunciado propósito de oferecer aos estudantes um maior envolvimento com as diferentes ciências que configuram a estrutura curricular. Dessa forma, ficou estabelecida a distribuição das disciplinas em quatro grandes núcleos: Disciplinas do Núcleo Específico de Formação Básica (grandes áreas da geografia físico-humana), Disciplinas do Núcleo Específico de Formação Profissional (área de ensino), Disciplinas do Núcleo Básico Complementar (diferentes áreas que complementam o saber geográfico, como história, língua portuguesa, matemática estatística) e Disciplinas do Núcleo de Opções Livres (UNIVERSIDADE ESTADUAL DO SUDOESTE DA BAHIA, 2003).

Este segundo documento (currículo em vias de reformulação) buscou ampliar os horizontes da ciência geográfica, num processo de retirada/inserção de disciplinas, cujas temáticas já eram debatidas nos eventos acadêmicos de todo o país. Nesse processo, identificou-se uma discussão em torno das problemáticas ambientais, das transformações nas esferas política e econômica globais, além das inovadas técnicas cartográficas, promovidas pelo avanço da ciência e da tecnologia. Era preciso estar preparado para se ensinar/aprender acerca desse dinâmico mundo, configurado por uma série de mutações e imprevisibilidades.

Paralelo a isso, se discutia, de maneira ainda mais expressiva, o problema da interdisciplinaridade. O curso de Geografia da UESB, buscando se adequar às novas demandas do ensino superior, trabalhava a reformulação do seu currículo com vistas, também, à superação das deficiências apresentadas pelo documento anterior, como, por exemplo, a questão das fragmentações. Era preciso propor sugestões viáveis e eficazes para resolvê-las. A criação de disciplinas específicas, cuja finalidade seria a de tecer as articulações necessárias entre as diferentes áreas estudadas no curso, surgiu como ponto de partida. Além disso, buscou-se consolidar o contato dos discentes com as mais variadas situações socioambientais, para que estes pudessem perceber, com mais clareza, a relação indissociável entre teoria e prática.

A Geografia Tradicional novamente entrava em cena, como motivo de questionamentos e debates acerca da sua perpetuação no âmbito da geografia desenvolvida na UESB. Via-se que, apesar de o currículo anterior ter sido produzido com base na influência do movimento crítico de renovação da geografia no Brasil (1970/1980), o problema clássico das dicotomias (urbano versus agrário, local versus global, aspectos físicos versus aspectos humanos) permanecia vigente.

Na tentativa de se resolver tal problema, a partir de então, foram criadas as disciplinas Vivências Geográficas, que passaram a ser ministradas ao longo dos seis primeiros semestres do curso. O intuito era o de fazer com que tais disciplinas fossem capazes de estabelecer pontos de integração com as demais, contribuindo para a formação de uma visão mais abrangente da geografia produzida. As "Vivências Geográficas" estavam inseridas em um dos quatro núcleos básicos, que separavam as diferentes áreas do conhecimento que compõem o currículo do curso, denominado "Disciplinas do Núcleo Básico Complementar", somando uma carga horária total de 180 horas/aula. Essas disciplinas, de acordo com o Projeto Pedagógico (UNIVERSIDADE ESTADUAL 
DO SUDOESTE DA BAHIA, 2003), visavam estabelecer relações interdisciplinares, articulando diferentes conteúdos trabalhados ao longo da graduação, numa lógica capaz de proporcionar o contato direto do estudante com diversas situações concretas.

Na prática, o resultado foi outro. As novas disciplinas, longe de romperem com as fragmentações, ajudaram a ampliá-las. Os professores que passaram a ministrá-las se viram diante da obrigação de organizar os conteúdos e os demais direcionamentos pedagógicos para arquitetarem as suas aulas, passando a desenvolver as Vivências Geográficas, de maneira completamente distante das demais disciplinas, numa demonstração clara de que a proposta original não havia sido compreendida.

No ano de 2007, por exemplo, discentes e professores, durante as aulas de Vivências Geográficas oferecidas naquele momento, chegaram a passar todo um semestre no laboratório de ensino do curso, projetando as mais variadas maquetes, dentre elas a da cidade de Vitória da Conquista - BA, sem que houvesse qualquer discussão acerca dos principais problemas que afligem o planeta - ou mesmo a cidade citada - pensados sob a ótica geográfica. Qual sentido teria essa atividade tão extensa, a qual exigia, por parte dos envolvidos, conhecimentos rasos sobre representações do relevo por meio dos desenhos das curvas de nível? Quais as conexões possíveis de serem feitas ao longo de um processo que envolvia, quase que exclusivamente, a orientação no trato com os materiais utilizados na confecção das maquetes? Verificava-se que o sentido da formação do licenciado em geografia passava pelo ensino de procedimentos didáticos, completamente dissociados das práticas da pesquisa e de suas conexões com a realidade mesma.

Com isso, a lógica da instrumentalização técnica (CANDAU, 2000), que ganhou espaço nos cursos de licenciatura do país ao longo da década de 1960/1970, mostrava a sua absurda continuidade no Curso de Geografia da UESB. A premissa de que cabia às universidades a missão de preparar professores para suprir a demanda das escolas e que, para tanto, era necessário "instruí-los", sobretudo, acerca das técnicas de ensino - uma efetiva formação crítica do professor, em muitos casos, era renegada - não havia sido superada pela geografia uesbiana. Conta-se ainda, nesse processo específico das disciplinas de Vivências, a ampliação da distância entre pesquisa e ensino, pois o tempo para a realização daquela era minado pelas atividades quase que exclusivas deste, cujo sentido se revelava estar voltado a ensinar a ensinar. Um modelo educacional calcado na lógica fragmentária da ideologia dominante.

Tal direcionamento foi marcado por profundos questionamentos e embates entre docentes e discentes, os quais se viram envolvidos numa atmosfera marcada, em muitos casos, por constantes conflitos. Esses conflitos foram de extrema importância para o desenvolvimento da geografia uesbiana, pois com eles se pôde compreender que os problemas das dicotomias e da interdisciplinaridade não seriam resolvidos com a simples inserção de novas disciplinas à estrutura curricular.

Portanto, através de muitos embates pôde-se perceber que a mera substituição de temas e disciplinas, consideradas novas, não seria capaz de produzir o efeito da superação das dicotomias da ciência geográfica, objeto de profundas críticas por parte de intelectuais representantes desta ciência. Via-se que ao curso de Geografia cabia rediscutir os propósitos do processo de formação docente por ele orientado, com base em reflexões/ações mais abrangentes.

\subsection{A segunda reformulação curricular e a construção das bases de uma "nova" geografia}

Diante das contradições e dos problemas internos expostos, o Curso de Geografia da UESB voltou a discutir a sua estrutura curricular, um ano após a implementação do currículo anterior. Para tanto, realizaram-se seminários envolvendo o corpo docente e discente do Curso. O objetivo era amadurecer, de maneira coletiva, propostas capazes de atender aos anseios da comunidade acadêmica e, por extensão, promover uma maior contribuição social a partir de um novo modo de pensar 
e fazer geografia. O resultado desse processo alcançou significativas modificações, aplicadas no primeiro semestre de 2012 (UNIVERSIDADE ESTADUAL DO SUDOESTE DA BAHIA, 2010). Notava-se o empenho de professores e estudantes em torno do movimento de ruptura de algumas práticas realizadas com base nas orientações curriculares, até então em vigor.

Somado a isso, existiam outros fatores influenciando esse processo, como o descontentamento de discentes com aquilo que estava sendo ensinado/aprendido, a vontade de determinados professores em ampliar o quadro de disciplinas, motivados principalmente pelo desejo de promover um maior aprofundamento da área de conhecimento em que atuavam. Acontece que esses objetivos não se revelam muito claros quanto "aos seus fundamentos filosóficos, o que, consequentemente, os tornam pouco compreensíveis no que concerne às respostas que se esperam do discente no final do curso" (PINTAUDI, 1999, p. 110). De todo modo, as propostas de reorientação do currículo seguiram sendo amplamente discutidas e, gradativamente, materializadas em forma de documentos.

Dessa maneira, tanto o Departamento quanto o Colegiado de Geografia, desde então, permaneceram na via das discussões/ações em torno da reelaboração da estrutura curricular, tendo em vista, principalmente, a busca por soluções acerca das lacunas apresentadas pelo currículo precedente. Com isso, diferentes disciplinas passaram a compor a estrutura da nova proposta, sendo que outras foram "parcialmente modificadas apresentando uma renovação em suas ementas e algumas foram suprimidas. Além disso, várias alterações na estrutura de créditos, carga horária e pré-requisitos foram feitas" (UNIVERSIDADE ESTADUAL DO SUDOESTE DA BAHIA, 2010).

Nesse terceiro documento, o debate em torno do distanciamento entre teoria e prática nos estudos geográficos não foi descartado. Ao contrário disto, foi posto como base primordial do movimento de reformulação curricular, tendo em vista a persistente permanência de problemas teórico-metodológicos no âmbito da ciência geográfica, cujos efeitos resultaram na própria afirmação das dicotomias e, a partir delas, da fragmentação das análises espaciais. Sabe-se que este esfacelamento dos estudos geográficos apresenta pouca contribuição para o processo de desenvolvimento intelectual e para a afirmação de um saber científico bem consolidado.

Desse modo, considerou-se a necessidade de refletir sobre os direcionamentos do saber geográfico, desenvolvidos na esfera acadêmica, para que fosse possível alcançar uma melhor compreensão acerca das teorias e métodos que fundamentam as análises da geografia. Além disso, o projeto discorreu sobre a importância de se estabelecer interações com outras áreas do conhecimento produzido na UESB, como forma de se garantir um processo de interdisciplinaridade aplicado no plano concreto. Esse objetivo se tenta alcançar, principalmente, através dos projetos de pesquisa e extensão e dos núcleos de estudos coordenados pelos professores do departamento que, divididos em áreas específicas, desenvolvem os seus projetos, abrindo espaço para que outros discentes e pesquisadores interessados no assunto possam participar da troca de conhecimentos.

Tendo em vista o aumento considerável de projetos de pesquisa produzidos pelos docentes do curso nos últimos anos, dentro dos quais são abordadas questões relativas aos mais variados aspectos da realidade, as necessárias interações com os demais campos científicos da universidade têm avançado significativamente, propiciando o enriquecimento do próprio curso de Geografia e da academia em geral.

Quando comparado com o projeto anterior, percebem-se importantes alterações nos conteúdos inscritos no Projeto de Reorientação Curricular - PRC. Isto, porque o Projeto Pedagógico anterior apresentava rasas considerações sobre as habilidades essenciais a serem alcançadas pelos estudantes do curso, demonstrando, inclusive, um estreito alinhamento com as ideologias burguesas no que se refere aos explícitos propósitos de conformar a formação do licenciando com as diferentes demandas do mercado, indicando a possibilidade de os estudantes atuarem como "planejadores" do território - expressão típica do projeto burguês. 
O discurso contido nesse documento seguiu tecendo considerações mais aprofundadas da realidade a partir da ênfase dada aos dinâmicos processos históricos, dentro dos quais se desenrolam os mais variados problemas geográficos, a serem analisados criticamente. Como exemplo segue o trecho seguinte, onde se discute as habilidades a serem desenvolvidas ao longo da graduação:

Busca-se compreender a realidade brasileira, enquanto produto concreto das relações capitalistas de produção, em que o país assume papel fundamental na divisão social do trabalho, principalmente a partir do projeto de desenvolvimento implementado pelo Estado a partir da segunda metade do século 20 . Nesse propósito, pode-se considerar que as mudanças nos padrões de produção, repercutem no espaço geográfico e constituem-se questões fundamentais para a Geografia e para o ensino de Geografia, mais especificamente. Dessa forma, a lógica da industrialização, o crescimento da população urbana, o avanço do capital no campo e seus rebatimentos nas formas de organização social existentes até então, passam a sofrer significativas transformações. Os efeitos da crise estrutural do capital e seu reflexo imediato - o desemprego estrutural - promovem modificações significativas no espaço geográfico, nas diferentes escalas, levando ao profissional de Geografia novos desafios na compreensão da realidade espacial. (UNIVERSIDADE ESTADUAL DO SUDOESTE DA BAHIA, 2010).

Entretanto, não se pode perder de vista os limites impostos pela legislação em vigor sobre as propostas contidas nessa nova reforma curricular. A título de exemplo, cabe citar as orientações contidas no Parecer CNE/CES n 492/2001, que define "as seguintes competências e habilidades gerais e específicas, sem a distinção prévia de modalidades, habilitações ou níveis de formação" (UNIVERSIDADE ESTADUAL DO SUDOESTE DA BAHIA, 2010):

Gerais

- Identificar e explicar a dimensão geográfica presente nas diversas manifestações dos conhecimentos;

- Articular elementos empíricos e conceituais, concernentes ao conhecimento científico dos processos espaciais;

- Reconhecer as diferentes escalas de ocorrência e manifestação dos processos geográficos;

- Planejar e realizar atividades de campo referentes à investigação geográfica;

- Dominar técnicas laboratoriais concernentes à produção e aplicação dos conhecimentos geográficos;

- Propor e elaborar projetos de pesquisa no âmbito de área de atuação da Geografia;

- Utilizar os recursos da informática;

- Dominar a língua portuguesa e um idioma estrangeiro no qual seja significativa a produção e a difusão do conhecimento geográfico;

- Trabalhar de maneira integrada e contributiva em equipes multidisciplinares.

Específicas

- Identificar, descrever, compreender, analisar e representar os sistemas naturais;

- Identificar, descrever, analisar, compreender e explicar as diferentes práticas e concepções concernentes ao processo de produção do espaço;

- Selecionar a linguagem científica mais adequada para tratar a informação geográfica, considerando suas características e o problema proposto;

- Avaliar representações ou tratamentos; gráficos e matemático-estatísticos;

- Elaborar mapas temáticos e outras representações gráficas;

- Dominar os conteúdos básicos que são objetos de aprendizagem nos níveis fundamental e médio;

- Organizar o conhecimento espacial adequando-o ao processo de ensino-aprendizagem em Geografia nos diferentes níveis de ensino. 
Percebe-se que não existe nenhuma referência relacionada ao importante papel da ciência geográfica, enquanto instrumento de transformação da realidade. Longe disso, o que se tem é a apresentação de uma série de orientações carregadas de significados conservadores, deixando - explícito ou não -, que à geografia cabe o dever de estudar, avaliar informações, "compreender", "descrever", "identificar", "explicar", "planejar", "reconhecer", sem interferir na realidade posta. Fato que traz à tona, mais uma vez, o dilema das permanentes dicotomias da escola tradicionalista da ciência geográfica, pois, ao se negar à ciência uma possibilidade transformadora, estabelece-se o distanciamento entre o conhecimento produzido na universidade e a sua relação direta com os reais dilemas societários, tão carentes de transformação e não somente de explicações ou ajustamentos.

Há, com isso, uma contínua resistência travada por grupos acadêmicos, formados, em geral, por professores e discentes que tentam estabelecer um projeto de universidade diferente daquele cunhado pelo Estado capitalista, cujos propósitos tangenciam os interesses específicos da classe dominante. As ações do Estado são legitimadas, sobretudo, através das leis, as quais funcionam limitando as formas de pensar/agir dos sujeitos como meio fundamental de perpetuação do sistema. Dessa maneira, evidencia-se uma constante e desigual luta no interior da universidade - em especial, da universidade pública - onde conformismos e inquietudes se repulsam. Portanto, a construção do currículo do curso é fruto dessa lógica dialética em que a via da resistência é complementar à do conservadorismo, apesar destas representarem forças desiguais.

Seguindo a sequência da Proposta de Reorientação Curricular verifica-se a apresentação de alterações importantes realizadas a partir do currículo anterior, evidenciando, por exemplo, a urgente retirada das disciplinas denominadas de "Vivências Geográficas Interdisciplinares", devido a problemas por elas apresentados ao longo do curso. Tais disciplinas foram substituídas por "Análise da Paisagem" e "História do Pensamento Geográfico", como forma de consubstanciar os conhecimentos acerca das teorias e métodos da geografia e, consequentemente, proporcionar aos estudantes uma visão mais ampla e aprofundada de tal ciência. Além dessa importante alteração, outras se consolidaram, a saber:

\footnotetext{
- Substituição das disciplinas Práticas de Ensino específicas de cada área por disciplinas de conteúdos específicos como Geografia Econômica, Cartografia Aplicada à Pesquisa Geográfica, Introdução à Geografia Física, Geografia da Bahia e Interpretação das Espacialidades em Análise Regio- nal. A prática de ensino foi contemplada nas ementas das disciplinas de conteúdo específico.

- Substituição da disciplina Leitura e Escrita de textos Acadêmicos I pela disciplina LIBRAS, em atendimento ao Decreto $n^{\circ} 5526$ de 22/12/2005, do Ministério da Educação e da Resolução CONSEPE nº 09/2009. A disciplina Leitura e Escrita de Textos foi para o rol das disciplinas optativas. Esta substituição deveu-se à necessidade de garantir a integralização do curso com 3.065 horas. Ademais destacamos que as disciplinas específicas buscam contemplar a leitura e escrita de textos acadêmicos.

- Supressão da disciplina Tópicos de Formação do Mundo Contemporâneo tendo em vista a superposição de conteúdos com as disciplinas de natureza específica do Curso. (UNIVERSIDADE ESTADUAL DO SUDOESTE DA BAHIA, 2010).
}

Houve um pequeno aumento da carga horária do curso, passando de 3045 para 3.065 horas, sendo que a duração mínima e máxima passaram, respectivamente, de três anos e meio e sete anos para uma duração mínima de quatro anos e máxima de seis para o turno matutino "que está estruturado em 8 (oito) semestres. Para o noturno, o tempo mínimo é de 4 (quatro) anos e meio e máximo de 6 (seis) anos e meio já que o currículo do curso noturno está estruturado em 9 (nove) semestres" (UNIVERSIDADE ESTADUAL DO SUDOESTE DA BAHIA, 2010). 
Em relação aos trabalhos de pesquisa realizados ao final do curso, como requisito obrigatório para obtenção do título de graduado, não houve alteração significativa. As atividades desenvolvidas pelas disciplinas da área passaram a ser dinamizadas a partir do sétimo semestre, aprofundando o problema concernente à relação entre o ensino e a prática da pesquisa, tão enraizado na memória do curso de Geografia. De maneira complementar, a disciplina "Seminários Temáticos" seguiu buscando proporcionar a discussão, reflexão e socialização dos conhecimentos produzidos ao longo das pesquisas realizadas ao final da graduação, apesar das limitações apresentadas anteriormente.

Fato importante é que o Curso de Geografia passou a proporcionar o contato dos estudantes com a realidade do ambiente de trabalho (escolas), através da oferta de disciplinas ligadas ao Núcleo de Estágio Supervisionado, a partir do segundo semestre (matutino) e do terceiro (noturno), diferente do que acontecia com o currículo anterior em que as disciplinas dessa área só eram oferecidas na segunda metade do curso, fato que contribuía para aprofundar o problema da formação fragmentária do discente.

Era preciso, também, resolver uma questão bastante recorrente no curso, relacionada à divisão conflituosa entre as disciplinas da Área de Ensino e as do Núcleo Específico e Complementar de Formação Básica, contidas no projeto antigo. Enquanto que estas últimas abrangiam os fundamentos teórico-metodológicos indispensáveis ao processo de formação científica específica em geografia, além dos conhecimentos de diferentes áreas, as primeiras tratavam dos conhecimentos educacionais e pedagógicos necessários à formação profissional do licenciado. Estavam presentes, posicionamentos antagônicos entre os docentes e discentes do curso. Verificavam-se aqueles que supervalorizavam as disciplinas ligadas, mais especificamente, ao quadro técnico da geografia, como cartografia, geologia, geomorfologia, climatologia, pedologia, fitogeografia, geografia urbana, geografia da população, etc. Esse grupo defendia a redução do número de disciplinas ligadas ao ensino, apesar de se tratar de um curso de licenciatura. Havia, também, os que se posicionavam no sentido oposto, ou seja, sugeriam a redução de disciplinas do quadro técnico e aumento das relacionadas à área de ensino. Isto evidencia que no interior da universidade ainda é bastante presente a concepção dicotômica que separa o bacharel, considerado pesquisador, do licenciado, res-ponsável por replicar conhecimentos, através das práticas de ensino, "apesar da falácia que aponta para a indissociabilidade entre pesquisa, ensino e extensão" (TRINDADE; OLIVEIRA, 2007, p. 74).

$\mathrm{Na}$ matriz curricular anterior, a divisão entre as duas áreas era muito mais evidente, o que causava grande confusão entre os discentes, os quais perdiam de vista o sentido da sua formação profissional, já que, nos primeiros semestres, participavam da produção de conhecimentos próprios da ciência geográfica, desenvolvidos sem qualquer relação com o ensino da geografia. Os estudantes só tinham contato com as disciplinas da área pedagógica no quarto semestre, ou seja, na metade da graduação. Apesar de os ingressantes terem conhecimento de que a sua formação em geografia estava voltada, em especial, ao campo da licenciatura, o antigo currículo não deixava isto claro. A impressão era de que se cursava bacharelado até a primeira metade do curso, enquanto que, na segunda, partia-se para a licenciatura. Tal situação acabava promovendo outro problema relacionado à carga excessiva das disciplinas do núcleo pedagógico, que se concentravam, sobretudo, a partir do sexto semestre, quando todas as disciplinas cursadas em tal fase carregavam conteúdos específicos da área de ensino. Essa carga excessiva acumulada nos momentos finais do curso foi fonte de inúmeros embates entre professores e discentes. Uns buscando superar essa lógica, outros tentando justificá-la.

Pensando também nisto, a equipe reunida em torno do Projeto de Reorientação Curricular materializou as alterações discutidas ao longo do processo e, com isso, houve uma redistribuição de 
disciplinas, proporcionando o contato, desde o início do curso até o seu encerramento, dos discentes com as disciplinas do núcleo pedagógico. Estas, por seu turno, foram desconcentradas a partir desse rearranjo, passando a ser estudadas, concomitantemente, com disciplinas de outras áreas ao longo de toda a graduação - exceção dos segundo e terceiro semestre. Essa nova distribuição permitiu que o licenciando compreendesse o sentido de sua formação desde o início de sua vida acadêmica, deixando "clara" a perspectiva primordial da formação de professores de geografia e não de bacharéis, como poderia parecer anteriormente. Ao mesmo tempo, ofereceu uma concepção mais ampla da ciência geográfica, pois permitiu enxergá-la de modo mais integrado - o aprender a ensinar a geografia articulado com os saberes estruturadores desta ciência.

Todos esses esforços dispensados em torno do Projeto de Reorientação Curricular resultaram em consideráveis avanços em relação à formação do licenciando. As propostas se pautaram no objetivo de (re)construir uma geografia capaz de oferecer conhecimentos/práticas que possibilitassem a compreensão das contradições do mundo e o desvelar das ideologias dominantes que têm contribuído no processo de perpetuação do status quo. Apesar disto, as determinações legais, situadas na via oposta desse processo, seguem limitando, sobremaneira, toda e qualquer proposta transformadora capaz de comprometer a ordem dominante e, por tabela, promovem a fragilização das lutas pela conclamada autonomia universitária.

\section{5 | CONSIDERAÇÕES FINAIS}

Essa análise sobre as estruturas curriculares do curso de Geografia da UESB revela/esconde memórias inscritas nesses importantes documentos. Memórias estas marcadas por disputas, contradições, reproduções, resistências e distorções do mundo real. Revela/esconde ainda, um constante processo de construção de uma ciência geográfica "crítica" - a partir do empenho de alguns poucos discentes e professores - permanentemente em vias de consolidação, cuja trajetória esteve marcada por avanços e retrocessos. Complementarmente, a leitura crítica dos currículos permite perceber a insistente continuidade de uma geografia parcelada, ainda carregada de ideologias dominantes, cujo sentido tem alcançado a reprodução massiva do capital, resultando também numa grande dificuldade dos discentes em compreender o (s) sentido (s) da ciência geográfica.

A construção dessa memória ideologizada da geografia não parte apenas dos processos de produção/reprodução do ensino-aprendizagem orientados por determinada matriz curricular. Esta é apenas uma das diversas formas encontradas pela ideologia dominante, de se manifestar, mas não a única, já que, assim como se infere das afirmações althusserianas (ALTHUSSER, 1969), a ideologia se materializa no próprio corpo dos indivíduos, através não somente das suas ideias, mas também do seu comportamento, estando o agir e o pensar dentro de uma mesma equação. É, portanto, na vivência dos estudantes do Curso de Geografia da UESB, ao longo da sua dinâmica cotidiana, desenvolvida dentro e fora do espaço acadêmico, que a memória (ideologizada) geográfica vai se consolidando e sendo produzida/reproduzida.

Entretanto, é preciso reafirmar, acima de tudo, a natureza contraditória de toda e qualquer dinâmica societária: o ser e o não ser concomitantes dos processos educacionais, enfim, a dialética inerente aos mecanismos relacionados aos movimentos de ensino-aprendizagem desenvolvidos, em especial, no âmbito da instituição universidade. Desse modo, crê-se possível a produção de alternativas sociais por meio da luta coletiva em prol da construção de uma universidade e de uma Geografia capazes de rejeitarem toda forma de ilusão, estabelecendo com isso, uma necessária resistência aos mecanismos de perpetuação e de expansão do capital. 
Para que os direcionamentos do ensino de geografia adquiram novos rumos e posturas mais condizentes com os propósitos da ciência geográfica e da educação brasileira, é, sobremodo importante que se imprima no envoltório das academias, novas reflexões e debates, visando a construção coletiva de uma base curricular capaz de contribuir, de modo mais adequado, com o processo ininterrupto de leitura, interpretação, compreensão e transformação consciente da realidade. Isto, feito de modo a considerar imprescindível a relação indissociável entre universidade, instituições de ensino básico e sociedade em geral. 


\section{REFERÊNCIAS}

ALTHUSSER, L. Ideologia e aparelhos ideológicos do Estado. Lisboa: Editorial Presença, 1969.

APPLE, M. W. Currículo e poder. Educação e Realidade, Porto Alegre, ano 14, n. 2, p. 46-57, jul./dez. 1989.

BRASIL. Instituto Nacional de Estudos e Pesquisas Educacionais Anísio Teixeira. Plano Nacional de Educação PNE 2014-2024 : linha de base. Brasília, DF: Inep, 2015. $404 \mathrm{p}$.

. Lei $n^{\circ}$ 9.394, de 20 de dezembro de 1996. Estabelece as diretrizes e bases da educação nacional. Diário Oficial da União. Brasília, DF, 23 dez. 1996.

Ministério da Educação e do Desporto. Secretaria de Educação Fundamental. Parâmetros Curri- culares Nacionais: Geografia. Brasília, DF: MEC; SEF, 1998.

CANDAU, V. M. Didática, currículo e saberes escolares. Rio de Janeiro: DP\&A, 2000.

GOODSON, I. Currículo: teoria e história. Petrópolis, RJ: Vozes, 1995.

KOSIK, K. Dialética do concreto. Rio de Janeiro: Paz e Terra, 1976.

LEI de diretrizes e bases para o ensino de $1^{\circ}$ e $2^{\circ}$ graus. Lei $n^{\circ}$ 5.692, de 11 de agosto de 1971. In: VALE, J. M. F. do et al. (Org.). Escola pública e sociedade. São Paulo: E. A. Lucci, 2002. p. 391-401.

OLIVEIRA, C. G. S. de. A geografia como disciplina: trajetória nos currículos escolares do brasil e o seu ensino como questões centrais da discussão. In: TRINDADE, G. A.; CHIAPETI, R. J. N. (Org.). Discutindo geografia: doze razões para se (re)pensar a formação do professor. Ilhéus: Editus, 2007.
PINTAUDI, S. M. Geografia: um currículo espetacular. In: CARLOS, A. F. A.; OLIVEIRA, A. U. de. (Org.). Reformas no mundo da educação: parâmetros curriculares e geografia. São Paulo: Contexto, 1999.

RAMIRES, R. R. A formação docente em geografia na PUCSP a partir do Projeto de Reorientação Curricular da licenciatura no período de 2005 a 2009. 2011. Tese (Doutorado em Educação) - Pontifícia Universidade Católica de São Paulo, São Paulo, 2011.

SANTOS, M. Por uma outra globalização: do pensamento único à consciência universal. 16. ed. Rio de Janeiro: Record, 2008.

TRINDADE, G. A.; OLIVEIRA, C. G. S. de. Ensino de Geografia e Reflexões Acerca da (Re)Construção do Currículo no âmbito da Licenciatura. In: TRINDADE, G. A.; CHIAPETI, R. J. N. (Org.). Discutindo geografia: doze razões para se (re)pensar a formação do professor. Ilhéus: Editus, 2007.

UNIVERSIDADE ESTADUAL DO SUDOESTE DA BAHIA. Projeto de Reorientação Curricular do curso de licenciatura plena em Geografia - PRC. Vitória da Conquista: UESB, 2010.

UNIVERSIDADE ESTADUAL DO SUDOESTE DA BAHIA. Projeto Político Pedagógico de Geografia - PPG. Vitória da Conquista: UESB, 2003. 